\title{
Oxidation of advanced intermetallic compounds
}

\author{
N.S. Bornstein \\ United Technologies Research Center, East Hartford, CT 06108, U.S.A.
}

\begin{abstract}
Intermetallic compounds with low densities and high melting temperatures are prime structural material candidates for advanced heat engines. The close link between crystal structure and mechanical properties has led the search for new cubic pseudo-binary transition metal aluminides. Compositing leads the way for improved mechanical properties of refractory metal silicides. In all cases there is a strong competition for oxide scale frequency between the energetic oxide formers of the intermetallic compounds. In the case of titanium aluminides, efforts are directed towards modification of the concentration of oxygen vacancies to reduce growth rates and influence scale dominance. Glass formers are added to the disilicides to promote scale fluidity to seal cracks which are pathways for oxidation.
\end{abstract}

\section{Introduction.}

The most successful intermetallics are coatings. The most successful coatings are the intermetallics based upon the aluminides of the transition metals notably nickel, cobalt and iron. The remarkable growth of the gas turbine superalloys is based in part upon the ability of the material engineer to concentrate efforts to improve mechanical properties and employ coatings to achieve acceptable oxidation and corrosion resistance.

Further increases in efficiency and performance of gas turbine engines is possible through the use of materials that can operate at higher temperatures and possess greater strength to weight ratios. Intermetallic compounds are candidate materials. The nickel aluminides are more refractory than the current transition element alloys. The aluminides of titanium promise higher strengths with lower densities, while composites based upon molybdenum disilicide offer high temperature strength and oxidation resistance. Thus the objective of this address is to identify current strengths and weaknesses in order to further promote the state-of-the-art.

\section{Oxidation resistance.}

Oxidation resistance is often the limiting factor that determines the life of high temperature structural metals and alloys. The kinetics, morphology and composition of the oxidation products are obtained from thermogravimetric analytical studies (TGA), light and electron microscopy studies, and various analytical techniques. All of the above are used to determine the rate of growth of the oxidation products. The rate of growth of the oxidation products are often described by a parabolic function and the relative merit of performance is commonly presented in pictorial form as a plot of the log of the parabolic scaling constant versus the reciprocal of the absolute temperature. 
Although the rate of growth of the oxide scale, determined from isothermal studies is a measure of performance; it is, at best, a poor yardstick. Oxidation resistance is not only a measure of the rate at which an oxide scale thickens, but includes the ability of the scale to resist the thermally induced stresses associated with cyclic behavior. A typical example is the relative behavior of the materials, $\mathrm{Ni}-15 \mathrm{Cr}-6 \mathrm{Al}$ and $\mathrm{Ni}-15 \mathrm{Cr}-6 \mathrm{Al}-0.1 \mathrm{Y}$. In isothermal tests both materials form alumina scales. However in a cyclic test the yttrium-containing alloy maintains its ability to form a protective adherent oxide scale. However the alumina scale on the yttrium free alloy spalls at the completion of each cycle (Fig. 1). Thus although both alloys form alumina scales, the alloy containing yttrium exhibits "oxidation resistance". If intermetallic compounds are to be structural components operating in oxidizing environments, they must exhibit both the necessary mechanical properties as well as oxidation resistance. It is therefore important to understand the factors that influence oxide scale adherence.

OXIDATION OF AS-CAST NICIAI AND NICIAYY ALLOYS AT $1150^{\circ} \mathrm{C}$

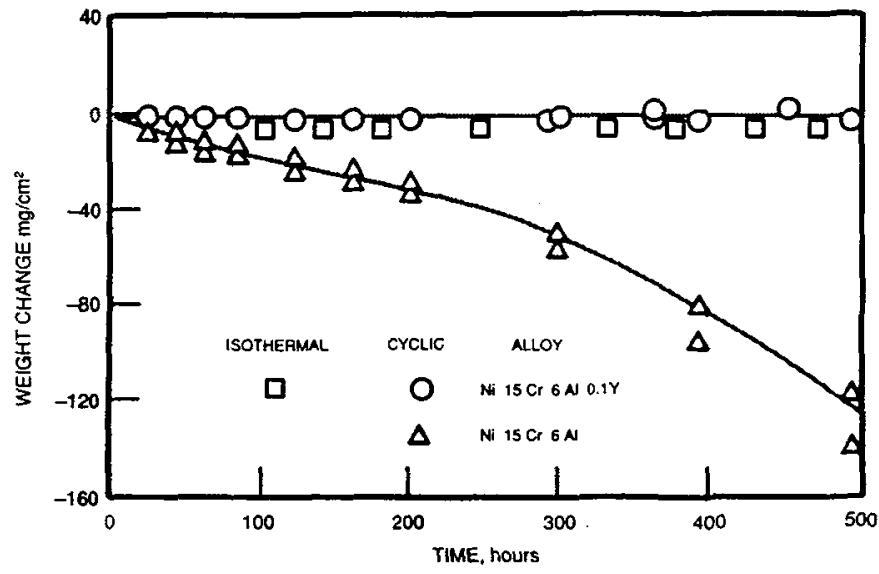

Fig. 1. - Yttrium greatly enhances oxide scale adherence.

\section{Alumina formers.}

3.1 NiCKel bASE AlloYs. - Tien et al. [1] describing cyclic oxidation says "violence is done on oxide scales during cyclic oxidation by growth and thermal stresses". It is well established that the addition of small quantities of certain elements and compounds greatly improves oxide scale adherence. The phenomena is called the "reactive element effect" (REE). A number of mechanisms have been proposed and reviewed [2, 3]. Yttrium is the most commonly used reactive element to impart scale spallation resistance to alumina forming alloys. $\mathrm{Re}-$ cently it has been proposed that the alumina scale that forms on the transition metal alloys and compounds is strongly bonded, but impurities present in the substrate promote oxide scale spallation. The principal impurity is sulfur. It is important to establish if the removal of sulfur below some critical level imparts oxidation resistance since it is not always commercially feasible to add reactive elements without incurring other liabilities. 
The sulfur model is the product of ONR-sponsored research to explain the improvement observed in oxide scale adherence when surfaces are laser processed [4]. The strength of the model is its simplicity. The model assumes the existence of a strong chemical bond between the alumina scale and the alloy substrate. The bond is weakened by sulfur, a tramp impurity, which segregates to the oxide scale interface. The mechanism by which sulfur weakens the bond is not described, however it is proposed that superior oxide scale adherence is achieved by reducing the activity of sulfur in the substrate either by removal of sulfur or uniting the sulfur with a potent sulfide former. The role of the REE is to unite with and thereby reduce the activity of sulfur in the substrate.

( $7500^{\circ} \mathrm{C}, 5$ MIN, $10^{-10}$ TORR)

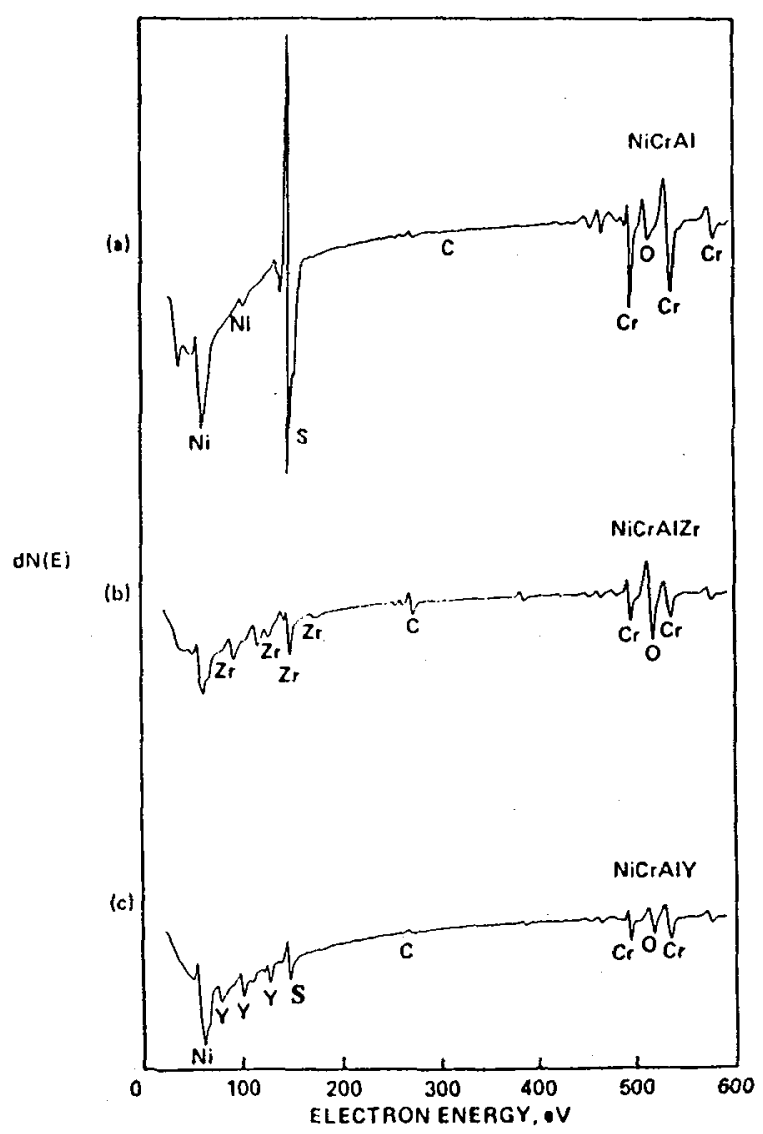

Fig. 2. - Auger spectra showing S, Zr or Y segregation.

Auger studies are used to demonstrate that the reactive elements reduce the activity of sulfur in $\mathrm{Ni}-\mathrm{Cr}-\mathrm{Al}$ alloys, figure 2 [5]. Other studies have shown that the addition of sulfur to NiCrAlY alloys prevents the alloy from forming spallation resistant scales. However the 
addition of more yttrium restores resistance to oxide scale spallation (Fig. 3). This data supports the sulfur-yttrium interaction. However the recent work of Smialek et al. [6] strongly indicates that the simple reduction in the concentration of sulfur in the matrix is sufficient to impart resistance to oxide scale spallation. The heat treatment of nickel base alloys in hydrogen environments was used to remove sulfur from the alloy, and the subsequent high temperature cyclic oxidation tests verified the formation of a spallation resistant oxide scale.

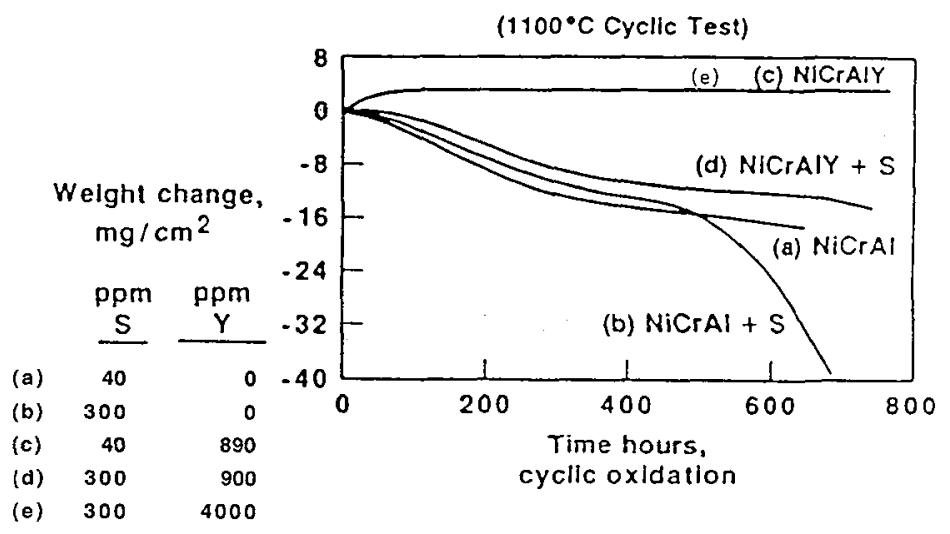

Fig. 3. - Effect of yttrium and sulfur content on the cyclic oxidation resistance of NiCrAl.

The intermetallic compound $\mathrm{NiAl}$ is quite brittle at low temperatures and rather weak at elevated temperatures. Nevertheless it is suggested for use in advanced applications as the matrix phase for metallic based composites. The face centered cubic intermetallic compound $\mathrm{Ni}_{3} \mathrm{Al}$, when alloyed with small quantities of boron, exhibits attractive mechanical properties over a wide range of temperatures. Although the oxidation behavior of $\mathrm{NiAl}$ has been extensively studied, further improvements, taking into account the role of sulfur, should be explored. The oxidation behavior of boron modified $\mathrm{Ni}_{3} \mathrm{Al}$ with respect to sulfur and oxide scale adherence should be investigated.

3.2 TITANiUm Aluminides. - Alloy designers are concerned with finding materials with superior properties. In the aircraft industry new light weight strong oxidation resistant materials are sought. Some of the most attractive aluminides from the view point of low density and high temperature potential are those in the Ti-Al system such as $\mathrm{Ti}_{3} \mathrm{Al}$ and TiAl. Their densities of 3.76 to $4.50 \mathrm{~g} / \mathrm{cm}^{3}$ are only half the densities of nickel and cobalt superalloys. Large weight savings are possible, however the use of titanium aluminides at high temperature is limited by relatively poor oxidation resistance.

Titanium and aluminium are both energetic oxide formers. It is generally agreed that alumina is the scale that forms on the surface of $\mathrm{TiAl}_{3}$. However this very brittle intermetallic compound draws little interest.

Meier et al. [7] using the criteria established by Wagner [8] and data available in the literature conclude that the solubility of aluminum in titanium in both the alpha and beta phases is insufficient for the alloy to develope an alumina protective external scale. The aluminum in the alloy is preferentially internally oxidized. Welsch et al. [9] as well as Choudhury et 
al. [10] studied the oxidation behavior of $\mathrm{Ti}_{3} \mathrm{Al}$ and found that the alloy formed primarily titania-rich scales. Moreover Welsch reports that even in the isothermal tests, the weight gain curves exhibit discontinuities due to cracking or spalling of the oxide layer. Nevertheless they were able to determine parabolic scaling constants and concluded that the principal scale is titania.

Meier reports that TiAl exposed in oxygen in the temperature range 800 to $1000{ }^{\circ} \mathrm{C}$ forms alumina scales. Moreover the scaling constant is comparable to that of other alumina formers such as NiAl. However when the temperature is increases above $1000^{\circ} \mathrm{C}$, the oxidation rate increases and the alloy forms titanium rich scales. Moreover the authors clearly identify an effect related to nitrogen. The same alloys exposed in air does not form alumina scales and the authors note that the effect of nitrogen on the selective oxidation of aluminum from TiAl is very much in need of further study.

Hanamura et al. [11] takes a different approach to improve the oxidation resistance of TiAl. They report that the alloy is a titania former. According to the authors the growth of titanium oxide occurs by the inward diffusion of oxygen ions through $\mathrm{TiO}_{2}$. Therefore the polyvalent elements of group $\mathrm{Vb}$ and $\mathrm{VIb}$ having higher valencies than $\mathrm{Ti}(4+)$, introduced into the titania scale, should reduce the concentration of oxide ion vacancies thereby reducing the oxidation rate. The authors report that the introduction of about $100 \mathrm{ppm}$ of selenium or tellurium is effective. It decreased the weight gain of TiAl exposed at $800^{\circ} \mathrm{C}$ by more than five-fold. Ikematsu et al. [12] also studied the effect of additions of phosphorus on the oxidation behavior of TiAl. They report that the addition of $500 \mathrm{ppm} \mathrm{P}$ also decreases the weight gain of the alloy by five-fold when exposed 500 hours at $900{ }^{\circ} \mathrm{C}$. Again the authors relate the improvement in performance to the reduction in the concentration of oxygen vacancies in $\mathrm{TiO}_{2}$. It is quite clear that the area of oxidation of titanium base intermetallics is quite complex and poorly understood.

\section{Silica formers.}

The refractory metals typified by niobium, tantalum, and molybdenum exhibit desirable high temperature properties. They are strong and ductile and can be formed and joined. Thus the refractory metals offer distinct advantages over ceramics. However the refractory metals and alloys lack oxidation resistance. The coatings developed to protect the refractory metals are based upon the oxidation performance of silicide intermetallic compounds.

The silicide coated refractory metals, exposed at elevated temperatures in highly oxidizing environments, do not offer the degree of reproducibility generally required for man rated applications. The issue is not the rate of oxidation of the coating. Unfortunately, the current family of silicide coatings contain numerous cracks which permit oxygen to enter into and react with the substrate alloy. The source of the cracks is generally believed to be stresses associated with the differences in coefficients of thermal expansion between the substrate and the coating. The changes in mechanical properties of the substrate limit the usefulness of the system long before the coating has been compromised. Nevertheless efforts should be directed toward improving the oxidation resistance of silicide coatings and manufacturing methods to produce defect - free coatings. Molybdenum disilicide is unique in that it is the principal constituent of a widely - used heating element for high temperature furnace applications and can be considered as a matrix material for high temperature composites. Coatings based upon the compound $\mathrm{MoSi}_{2}$ differ from other silicides in that scale is composed of only silica. According to Lavendel et al. [13] the formation of essentially pure silica scales on $\mathrm{MoSi}_{2}$ is the result of the selective oxidation due primarily to the large differences in thermodynamic 
stabilities of silica and molybdenum trioxide (Tab. I). They argue that since the free energy of formation of silica is much greater than the oxides of molybdenum, the available oxygen will partition itself strongly in favor of the formation of silica. The situation however is not true for other refractory silicides such as niobium or tantalum. The standard free energies of formation of the oxides of tantalum and niobium are nearly the same as that of silica. Thus according to the authors, the available oxygen will tend to partition approximately equally between the metal and silicon and there will be no selective oxidation of either component. Of course kinetics are overlooked as well as the fact that of the refractory metal oxides, only molybdenum trioxide is volatile. Molybdenum trioxide melts at $795^{\circ} \mathrm{C}$ and boils at $1280^{\circ} \mathrm{C}$. Laslty Grabke et al. [14] studied the oxidation behavior of chromium disilicide. They report that the intermetallic compound forms a protective chromia scale in the temperature range from 900 to $1050^{\circ} \mathrm{C}$. They note the absence of selective oxidation of silicon even though the activity of chromium in the substrate is low and the silicon activity and concentration are high.

Table I. - Free energy of formation of various oxides at $1500 \mathrm{~K}$.

\begin{tabular}{|c|c|}
\hline Oxide & $-\Delta F$ kCal/g. atom O \\
\hline $\mathrm{SiO}_{2}$ & 73.15 \\
$\mathrm{Ta}_{2} \mathrm{O}_{5}$ & 66.9 \\
$\mathrm{Nb}_{2} \mathrm{O}_{5}$ & 59.98 \\
$\mathrm{MoO}_{3}$ & 31.96 \\
$\mathrm{Cr}_{2} \mathrm{O}_{3}$ & 59.53 \\
\hline
\end{tabular}

"Pest" oxidation first described by Fitzer [15] involves the disintegration of the material into small disilicide particles, covered by a loose, voluminous scale. The pest phenomenon occurs in many intermetallic compounds over a wide temperature range that is specific for each material. The reaction has been studied and the review by Krier [16] presents a number of observations. It is suggested that the reaction is caused by the contamination of the $\mathrm{SiO}_{2}$ scale by $\mathrm{MoO}_{3}$ for the $\mathrm{MoSi}_{2}$ system and $\mathrm{WO}_{3}$ for $\mathrm{WSi}_{2}$. Pest is found to occur in the temperature range in which the vapor pressure of the volatile oxide is insufficient for its vaporization from the $\mathrm{SiO}_{2}$. The upper temperature limit for pest is approximately that at which the oxide has a vapor pressure of $\exp (-3)$ atm; $780^{\circ} \mathrm{C}$ for $\mathrm{MoO}_{3}$ and $1288^{\circ} \mathrm{C}$ for $\mathrm{WO}_{3}$.

The most extensive study of the pest reaction of $\mathrm{MoSi}_{2}$ was conducted by Berkowitz et al. $[17,18]$. Their investigation covered the temperature range of $450-650^{\circ} \mathrm{C}$. Failure due to pest is found in oxygen, but not in nitrogen, carbon dioxide, carbon monoxide or argon. Moreover the rate of disintegration is strongly dependent upon the oxygen partial pressure.

The pest reaction has been eliminated in several disilicides by alloy additions. Zeitch [19] found that the addition of 5-15 pct $\mathrm{MoGe}_{2}$ stopped pest in $\mathrm{MoSi}_{2}$. In addition, high temperature oxidation produced a $\mathrm{GeO}_{2}-\mathrm{SiO}_{2}$ glass surface layer with a higher coefficient of thermal expansion and a lower viscosity than that of pure $\mathrm{SiO}_{2}$. This significantly improved the cyclic oxidation behavior.

Schlichting [20] reported that pest could be eliminated by keeping the porosity of sintered material to very low levels. 
In conclusion, intermetallic compounds offer unique and desirable properties and could very well replace many alloys in the near future provided that the promise of improved resistance to oxidation and corrosion can be realized.

\section{References}

[1] TrEN J.K. and DAVIDSON J.M., Stress Effects and the Oxidation of Metals. J. Cathcart Ed. (Metallurgical Society AIME, 1974) p.200.

[2] Whittle D.P. and Stringer J., Phil. Trans. R. Soc. London A 295 (1980) 309.

[3] Stringer J., Mater. Sci. Eng. A 120 (1989) 129.

[4] SMeggil J., Funkenbush A. and BORNSTEIN N.S., Studies of Adherent Oxide Scales, ONR Contracts N00014-82-C-0618 and N00014-85-C-0421 (1982-1987).

[5] Smialek J., Proceedings of the Symposium on High Temperature Materials Chemistry-IV, Z. Munie, D. Cubicciotti and H. Tagawa Eds. (Electrochem. Soc. 1988) p. 241.

[6] Smialek J., Tubbs B.K. and Smialek J., Corrosion and Particle Erosion at High Temperature Proceedings (TMS-AIME, 1989).

[7] Meier G.H., APpalonia D., Perkins R. and Chiang K., Oxidation of High Temperature, Intermetallics, T. Grobstein and J. Doychak Eds. (TMS, 1988) 185.

[8] WAGNER C., Z. Electrochem 63 (1959) 772.

[9] WELSCH G. and KAHVECI A.I., Oxidation High Temperature Intermetallics, T. Grobstein and J. Doychak Eds. (TMS, 1988) p.207.

[10] Choudhury N.S., Graham H.C. and HinZe J.W., Properties of High Temperature Alloys, Z.A. Foroulis and F.S. Petit Eds. (Electrochem. Soc., 1976) p.668.

[11] Hanamura T., Ikematsu Y., Morikawa H., Tanino M. and Takamura J., Proceedings of the International Symposium on Intermetallic Compounds, (JIMIS-6) O. Izumi Ed. (Japan Institute of Metals, 1991) p.179.

[12] Ikematsu, Hanamura Y.T., Morikawa H., Tanino M. and TakamuRa J., Proceedings of the International Symposium on Intermetallic Compounds, O. Izumi Ed. (Japan Institute of Metals, 1991) 191.

[13] LAVENDEL H.W. and Grant A., Elliot Trans Aime 239 (1967) 143.

[14] GRABKe H.J. and BRUMM M., Oxidation of High Temperature Intermetallics, T. Grobstein and J. Doychak Eds. (TMS, 1988) p.245.

[15] Fitzer E., Plansee Proc. 2nd Seminar, Reutte/Tyrol (Permagon Press, London, 1955) p.56.

[16] KrIER C.A., Coatings for the Protection of Refractory Metals from Oxidation, DMIC report 162 (Nov. 1961).

[17] Berkowitz-Mattuck J.B., Blackburn P.E. and LeE D., Refractory Metals and Alloys Part IV (Gorden and Breach London, 1969) p.1062.

[18] Berkowitz-Mattuck J.B., Rosseti M. and LeE D., Met. Trans. 1 (1970) 479.

[19] ZeitCH K., PhD Thesis Universitat Karlsruhle (1970).

[20] Schlichting J., High Temp. High Pressure 10 (1978) 241. 